\title{
Primitive Early Eocene bat from Wyoming and the evolution of flight and echolocation
}

\author{
Nancy B. Simmons ${ }^{1}$, Kevin L. Seymour ${ }^{2}$, Jörg Habersetzer ${ }^{3} \&$ Gregg F. Gunnell ${ }^{4}$
}

Bats (Chiroptera) represent one of the largest and most diverse radiations of mammals, accounting for one-fifth of extant species ${ }^{1}$. Although recent studies unambiguously support bat monophyly ${ }^{2-4}$ and consensus is rapidly emerging about evolutionary relationships among extant lineages ${ }^{5-8}$, the fossil record of bats extends over 50 million years, and early evolution of the group remains poorly understood ${ }^{5,7}$. Here we describe a new bat from the Early Eocene Green River Formation of Wyoming, USA, with features that are more primitive than seen in any previously known bat. The evolutionary pathways that led to flapping flight and echolocation in bats have been in dispute ${ }^{7-18}$, and until now fossils have been of limited use in documenting transitions involved in this marked change in lifestyle. Phylogenetically informed comparisons of the new taxon with other bats and non-flying mammals reveal that critical morphological and functional changes evolved incrementally. Forelimb anatomy indicates that the new bat was capable of powered flight like other Eocene bats, but ear morphology suggests that it lacked their echolocation abilities, supporting a 'flight first' hypothesis for chiropteran evolution. The shape of the wings suggests that an undulating gliding-fluttering flight style may be primitive for bats, and the presence of a long calcar indicates that a broad tail membrane evolved early in Chiroptera, probably functioning as an additional airfoil rather than as a preycapture device. Limb proportions and retention of claws on all digits indicate that the new bat may have been an agile climber that employed quadrupedal locomotion and under-branch hanging behaviour.

The Green River Formation of Wyoming has produced many spectacular fossils, including Icaronycteris index, widely regarded as the oldest and most primitive known bat ${ }^{9}$. Icaronycteris comes from the Fossil Butte Member of the Green River Formation, late early Eocene epoch, about 52.5 Myr ago ${ }^{9,19,20}$. Recently a new bat was discovered in the Fossil Butte Member that differs from Icaronycteris and other Eocene bats in being larger, having more primitive limb proportions and basicranium, and possessing well- developed claws on all wing digits. Because it cannot be assigned to any existing taxon, we here describe it as a new family, genus and species.

\section{Order Chiroptera}

Family Onychonycteridae fam. nov.

Onychonycteris finneyi gen. et sp. nov.

Etymology. Onycho (Greek): clawed; nycteris (Greek): bat. The genus name refers to the well-developed claws present on all hand digits. The specific epithet is given in honour of Bonnie Finney, who collected the holotype.

Holotype. ROM 55351A,B (Fig. 1 and Supplementary Figs 1-3), part and counterpart of a nearly complete, articulated skeleton including skull with lower jaws, found on 21 August 2003 at Finney Quarry, Lincoln County, Wyoming, USA.

Referred material. A specimen in a private collection also represents O. finneyi (Supplementary Fig. 4). First-generation casts of this specimen are housed in the American Museum of Natural History (AMNH 142467), in the University of Michigan, Museum of Paleontology (UM 12405), in the Royal Ontario Museum (ROM 55055) and at Fossil Butte National Monument (FOBU 9840).

Horizon and age. Both specimens are from the Sandwich Beds, Fossil Butte Member, Green River Formation, late early Eocene (Lostcabinian, Wasatchian Biochron Wa-7).

Diagnosis. Differs from all other known bats in having large claws on wing digits I, II and III, and small but distinct claws on digits IV and V. Cochlea and orbicular apophysis relatively small; stylohyal with small, rounded cranial tip; metacarpal formula (shortest to longest) I:II:III:IV:V; second phalanx longer than first phalanx in wing digits II-IV, first phalanx longer than the second in digits I and V; manubrium with keel-like ventral process; hind legs long and robust with complete fibula; feet with digit I shorter than digits II-V; calcar present; tail long.

Description and comparisons. Onychonycteris finneyi is a mediumsized bat that is substantially larger than most other known Eocene bats (Supplementary Table 1). The dentition is tribosphenic and resembles that of other Eocene chiropterans (Fig. 1b). The dental formula is $\mathrm{I} 2 / 3, \mathrm{C} 1 / 1, \mathrm{P} 3 / 3, \mathrm{M} 3 / 3$. In comparison with other bats including most Eocene taxa, Onychonycteris has a relatively small cochlea (Fig. 2). Unlike other Eocene bats ${ }^{9}$, Onychonycteris has a malleus with blunt and rounded orbicular apophysis that is relatively small, and a stylohyal bone that lacks any paddle-like expansion of the cranial tip (Fig. 1b).

The axial skeleton of Onychonycteris is similar to Icaronycteris with 7 cervical, 12 thoracic, 7 lumbar and 12 or 13 caudal vertebrae. The ventral process of the manubrium forms a laterally compressed keel (Fig. 1c). Rib and vertebral fusions common in several bat lineages are absent in Onychonycteris. The scapula resembles that of Icaronycteris, although it is not possible to determine whether a dorsal articular facet is absent in Onychonycteris as in Icaronycteris.

The morphology of wing elements in Onychonycteris is similar to that in other bats. As in Icaronycteris and Archaeonycteris, the trochiter (= greater tuberosity) of the humerus extends to the level of the proximal edge of the head, which is round in medial view. Each wing digit has three ossified phalanges. Digits I-III terminate in large claws, with smaller claws on digits IV-V. This pattern is unique among bats. With the exception of some pteropodids that retain a claw on digit II, all extant bats lack claws on digits II-V. Icaronycteris has a well-developed claw on digit II, but digits III-IV terminate in tiny ossifications that are not claw shaped. Archaeonycteris has a claw on digit II but lacks ossified third phalanges on the remaining digits. 
a

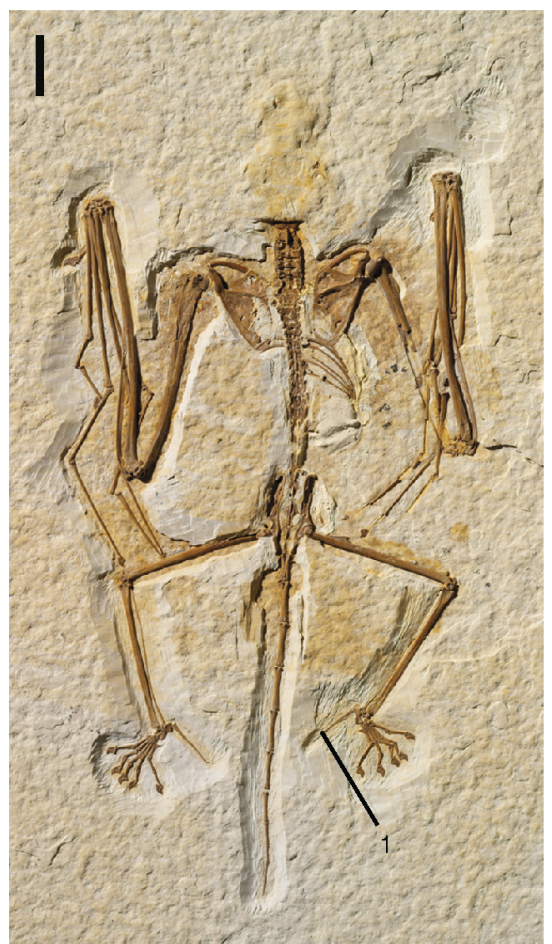

b

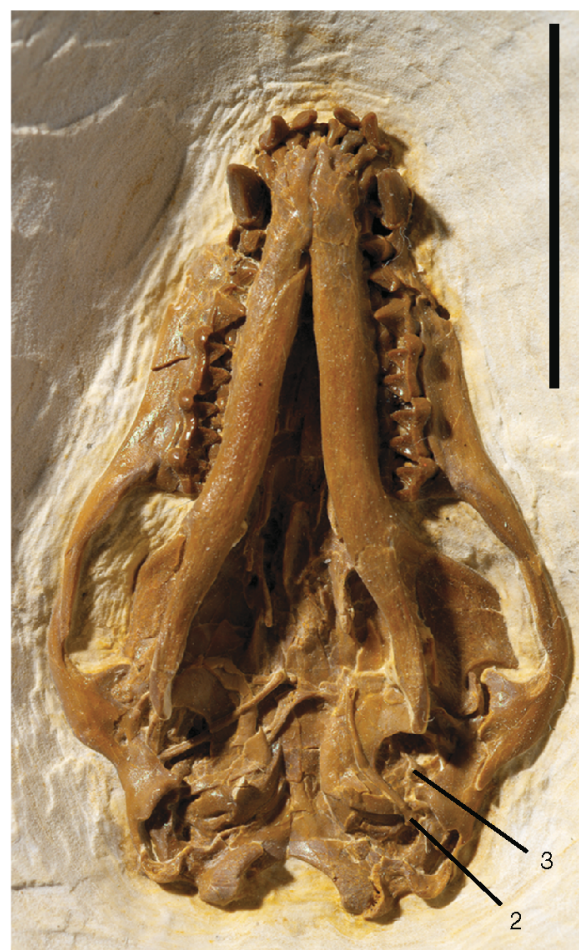

c

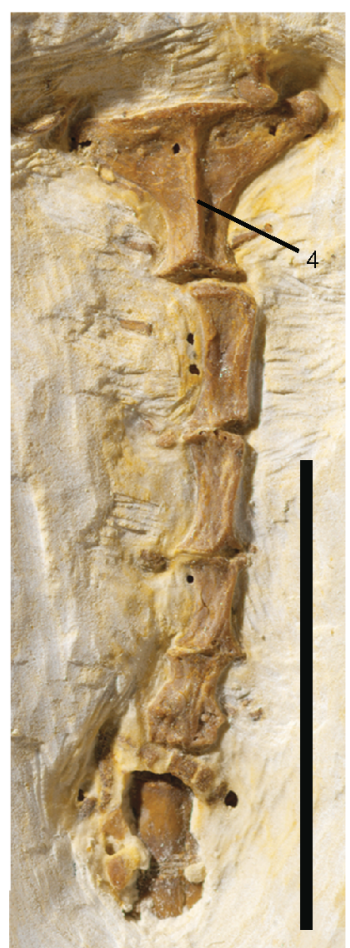

Figure 1 | Holotype of Onychonycteris finneyi (ROM 55351A). a, Skeleton in dorsal view. b, Skull in ventral view. c, Sternum in ventral view. Scale bars, $1 \mathrm{~cm}$. All elements are preserved on a single slab with the skeleton exposed on one side, and the skull and sternum on the reverse. The counter-part slab

Palaeochiropteryx and Hassianycteris lack ossified third phalanges on digits II-IV. The metacarpal formula (I:II:III:IV:V) in Onychonycteris is unique among Eocene bats. The second phalanx is longer than the first phalanx in digits II-IV, whereas the first phalanx is longer than
(ROM 55351B, not shown) preserves impressions of parts of the dorsal aspect of the skeleton. Features labelled: 1, calcar; 2, cranial tip of stylohyal; 3 , orbicular apophysis of malleus; 4 , keel on manubrium of sternum.

the second in digits I and V. In this respect Onychonycteris resembles Tachypteron $^{21}$. The wings of Onychonycteris were relatively short and broad with a very low aspect ratio index of 1.74, a low wingtip area ratio of $0.51-0.53$, and a low wingtip length ratio of 0.77 (Supplementary Table 2).

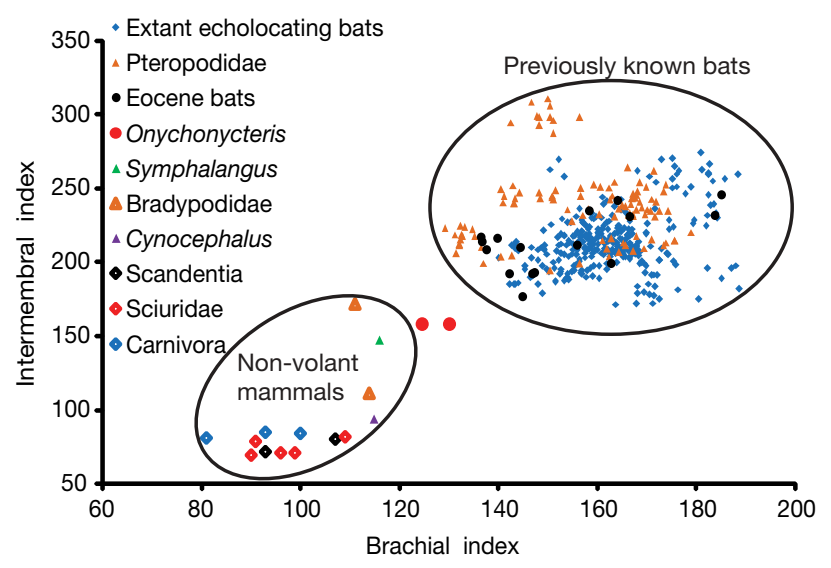

Figure 3 | Limb proportions in Onychonycteris compared with those of other bats and selected non-volant mammals. Intermembral index, defined as $100 \times($ radius length + humerus length $) /($ femur length + tibia length $)$, describes the relative proportions of the forelimb and hindlimb; brachial index, defined as $100 \times$ radius length/humerus length, describes the relative length of the forearm with respect to the upper arm. In overall limb proportions, Onychonycteris (red circles) falls midway between previously known bats and forelimb-dominated mammals that climb but do not fly (for example, Bradypodidae, Cynocephalus and Symphalangus). Typical scansorial mammals (for example, Scandentia, Sciuridae and Carnivora) have lower indices. Eocene bats indicated by black circles include Icaronycteris, Archaeonycteris, Palaeochiropteryx and Hassianycteris.
Figure 2 | Relative sizes of cochlea in extant and fossil bats. Cochlear size is known to be correlated with echolocation behaviour; non-echolocatin
bats (Pteropodidae) tend to have smaller cochleae than bats that use laryngeal echolocation (Rhinolophoidea, Emballonuroidea, Noctilionoidea and Vespertilionoidea) ${ }^{9,22-24}$. Onychonycteris (red circle with arrow) has a cochlea that is similar in size to those seen in Pteropodidae and smaller than observed in most echolocating bats. Icaronycteris (black circle on Pteropodidae regression line) has a similarly small cochlea. In contrast, other Eocene bats (Archaeonycteris, Palaeochiropteryx, Hassianycteris, Tachypteron and Tanzanycteris; black circles) have proportionately larger cochlea. See Supplementary Figs 7-9 for additional information. 
The limb proportions of Onychonycteris are unique among bats, being intermediate between all other known bats and forelimbdominated non-volant mammals (Fig. 3). Elongation of the radius is less pronounced than in other bats, and the hindlimb is proportionally longer. The pelvis of Onychonycteris resembles that of other bats and the hindlimbs are rotated outwards as in all known chiropterans ${ }^{2}$.

The feet of Onychonycteris are similar to those of other bats except that the overall length of the first digit is shorter than the other digits. In this respect Onychonycteris resembles Icaronycteris rather than extant bats, in which all five toes are subequal in length. The holotype of Onychonycteris has a relatively elongate calcar, a pattern common to many bats including Palaeochiropteryx and Hassianycteris. A calcar has never been observed in Icaronycteris or Archaeonycteris, but this may be an artefact of preservation.

Phylogenetic analyses based on morphological data indicate that Onychonycteris is the most basal bat presently known and is the sister group of the clade including Icaronycteris and all other extant and extinct bat lineages (Supplementary Fig. 5). Because morphologybased phylogenies of extant bats conflict with those based on gene sequences $^{4-9}$, we also conducted a phylogenetic analysis with the use of a molecular scaffold. The topology of the resulting tree (Fig. 4 and Supplementary Fig. 6) confirms the basal position of Onychonycteris within Chiroptera.

The evolution of flapping flight and laryngeal echolocation in bats has been the subject of debate. Three competing hypotheses have been proposed to explain the sequence of steps that lead to these key adaptations: 'flight-first', 'echolocation-first' and the 'tandem-

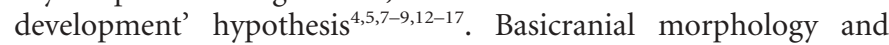
stomach contents suggest that at least six Eocene bat taxa (Icaronycteris, Archaeonycteris, Palaeochiropteryx, Hassianycteris, Tachypteron and Tanzanycteris) were echolocating bats ${ }^{9,21-25}$. Recent phylogenetic analyses including Eocene bats have either concluded that laryngeal echolocation is primitive for Chiroptera ${ }^{4,5}$ or could not rule out that possibility ${ }^{7}$. The basicranial region of Onychonycteris indicates that it has a relatively small cochlea similar to that seen in non-echolocating bats (Pteropodidae) but smaller than those found in most echolocating taxa (Fig. 2). Icaronycteris

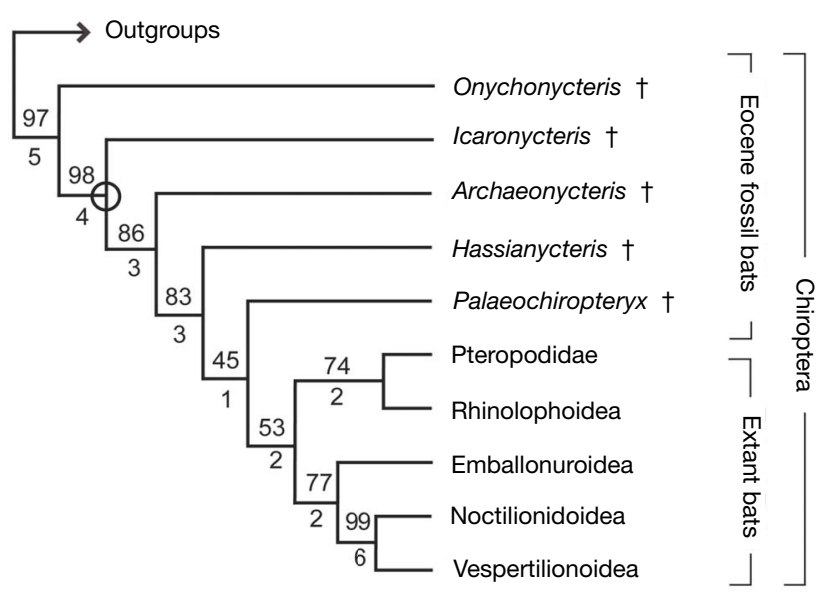

Figure 4 | Phylogenetic position of Onychonycteris and other Eocene fossils with respect to extant bat lineages. Relationships of fossil taxa to extant families (here grouped into superfamilies) were constrained by using a backbone scaffold tree derived from molecular studies. Numbers above branches are bootstrap values; numbers below branches are Bremer values. Derived features present in Icaronycteris, Archaeonycteris, and other extinct and extant bats (clade defined by node circled on tree) but absent in Onychonycteris include the following: enlarged orbicular apophysis on the malleus; stylohyal element with an expanded, paddle-like cranial tip; enlarged cochlea; ribs with posterior laminae; claws absent on forelimb digits III-V. and Archaeonycteris have cochleae that also fall into the zone of overlap between echolocating and non-echolocating bats, but these taxa share two additional derived features linked with echolocation $^{9,23}$ : an enlarged orbicular apophysis on the malleus, and a stylohyal element with an expanded, paddle-like cranial tip, both of which are absent in Onychonycteris (Fig. 1b). In the absence of these traits, there is no unambiguous evidence that Onychonycteris was capable of laryngeal echolocation.

Onychonycteris was clearly capable of powered flight, on the basis of the morphology of the manus, the shape of the rib cage, the faceted infraspinous fossa of the scapula, the robust clavicle and the keeled sternum, all of which are derived features intimately associated with the chiropteran flight apparatus ${ }^{9,15,26}$. This suggests that powered flight evolved early in the bat lineage, with echolocation evolving later (after the divergence of Onychonycteris), thus supporting the 'flight-first' hypothesis for chiropteran evolution. The conclusion that flight evolved before echolocation in the chiropteran lineage is consistent with studies of flight, ventilation and echolocation in living bats, which have suggested that echolocation may be too energetically costly to be sustained in the absence of flight ${ }^{13,14}$.

The low-aspect-ratio wings and relatively short and small wingtips of Onychonycteris are similar to those of extant mouse-tailed bats (Rhinopomatidae; Supplementary Fig. 10), which have an unusual undulating flight style in which fluttering is alternated with gliding ${ }^{10,12,27,28}$. In contrast, most extant microbats do not commonly glide $^{10}$. On anatomical and aerodynamic grounds, gliding has been proposed as a probable intermediate step in the development of powered flapping flight in bats from a non-flying ancestry ${ }^{9,12,15,27,28}$. An undulating gliding-fluttering flight style reduces energy costs at most flight speeds and permits an animal to fly slowly most economically ${ }^{29}$. This flight style may represent both a functional and an evolutionary intermediate between gliding and continuous flapping flight in the chiropteran lineage.

The discovery of Onychonycteris indicates that claws on digits III-V were lost after powered flight evolved. The limb proportions indicate that elongation of the forearm (radius + ulna) and hand bones (metacarpals + phalanges) continued after powered flight evolved, and the very-low-aspect-ratio wings of Onychonycteris suggest that higher-aspect-ratio wings (including the long, narrow wings seen in Eocene forms such as Hassianycteris ${ }^{11,12}$ and Tachypteron ${ }^{21}$ ) were derived later in chiropteran evolution.

Reduction in the relative size of the hind limbs also continued after the evolution of powered flight. The limb proportions, the robust fibula and the retention of wing claws seen in Onychonycteris suggest that it was probably capable of more agile non-volant locomotion (climbing either along tree branches or under them) than most other bats, including other Eocene taxa, and may have incorporated quadrupedal locomotion ${ }^{30}$ and under-branch hanging ${ }^{15}$ into its locomotory and roosting behaviour.

The calcar is a neomorphic element that supports the uropatagium (tail membrane) in most extant bats ${ }^{18,26}$. The presence of a long calcar in Onychonycteris indicates that the uropatagium, used by many bats to capture prey in flight ${ }^{9,26}$, was present in the earliest bats, contra previous reconstructions ${ }^{9,11,12,18}$. Because aerial hawking for insects requires sophisticated echolocation capabilities $9,14,16,17,24$ that were seemingly beyond the abilities of Onychonycteris, the uropatagium may instead have evolved as an additional airfoil to increase lift and reduce wing loading during powered flight ${ }^{10,26}$ or to help with turning and braking ${ }^{26}$, and was only later incorporated into the aerial insect capture apparatus by echolocating bats.

The morphology of the dentition suggests that Onychonycteris was insectivorous, like other Eocene bats. Lacking laryngeal echolocation, Onychonycteris probably detected its prey by vision, olfaction or passive auditory cues. It is not known whether the ancestors of bats were nocturnal, diurnal or crepuscular ${ }^{14}$. Living pteropodids, which forage and navigate while flying at night by using vision rather than echolocation, are characterized by enlarged eye orbits, and a diurnal 
bat ancestor might be expected to have orbits intermediate in size between those of echolocating bats and pteropodids ${ }^{14}$. Unfortunately, orbital size in Onychonycteris cannot be estimated because of post-mortem crushing of both known specimens.

\section{METHODS SUMMARY}

Skeletal measurements were made with standard methods. Cochlear and basicranial widths were determined from X-ray microradiographs and, for Onychonycteris, measurements of external features of the basicranium. Phylogenetic analyses were based on parsimony analyses of a morphological data set of 207 characters scored in all extant bat families and four Eocene fossi genera. Five outgroups (Tupaia, Cynocephalus, Erinaceus, Sus and Felis) were included to root trees. The data were analysed with heuristic parsimony algorithms, and clade support was assessed with bootstrap and decay methods.

Full Methods and any associated references are available in the online version of the paper at www.nature.com/nature.

\section{Received 21 September; accepted 10 December 2007.}

1. Simmons, N. B. in Mammal Species of the World: a Taxonomic and Geographic Reference (eds Wilson, D. E. \& Reeder, D. M.) 312-529 (Johns Hopkins Univ. Press, Baltimore, MD, 2005)

2. Simmons, N. B. The case for chiropteran monophyly. Am. Mus. Novitat. 3103, 1-54 (1994).

3. Murphy, W. J. et al. Molecular phylogenetics and the origin of placental mammals. Nature 409, 614-618 (2001).

4. Teeling, E. C. et al. Molecular evidence regarding the origin of echolocation and flight in bats. Nature 403, 188-192 (2000).

5. Springer, M. S., Teeling, E. C., Madsen, O., Stanhope, M. J. \& de Jong, W. W. Integrated fossil and molecular data reconstruct bat echolocation. Proc. Natl Acad. Sci. USA 98, 6241-6246 (2001).

6. Van Den Bussche, R. A. \& Hoofer, S. R. Phylogenetic relationships among recent chiropteran families and the importance of choosing appropriate out-group taxa. J. Mamm. 85, 321-330 (2004).

7. Eick, G. N., Jacobs, D. S. \& Matthee, C. A. A nuclear DNA phylogenetic perspective on the evolution of echolocation and historical biogeography of extant bats (Chiroptera). Mol. Biol. Evol. 22, 1869-1886 (2005).

8. Teeling, E. C. et al. A molecular phylogeny for bats illuminates biogeography and the fossil record. Science 307, 580-584 (2005).

9. Simmons, N. B. \& Geisler, J. H. Phylogenetic relationships of Icaronycteris, Archaeonycteris, Hassianycteris, and Palaeochiropteryx to extant bat lineages, with comments on the evolution of echolocation and foraging strategies in Microchiroptera. Bull. Am. Mus. Nat. Hist. 235, 1-182 (1998).

10. Norberg, U. M. \& Rayner, J. M. V. Ecological morphology and flight in bats (Mammalia: Chiroptera): wing adaptations, flight performance, foraging strategy and echolocation. Phil. Trans. R. Soc. B 316, 335-427 (1987).

11. Habersetzer, J. \& Storch, G. Klassifikation und funktionelle Flügelmorphologie paläogener Fledermäuse (Mammalia, Chiroptera). Cour. Forsch.-Inst. Senckenberg 91, 11-150 (1987).

12. Norberg, U. M. in European Bat Research (eds Hanák, V., Horácek, I. \& Gaisler, J.) 197-211 (Charles Univ. Press, Praha, 1989).

13. Speakman, J. R. \& Racey, P. A. No cost of echolocation for bats in flight. Nature 350, 421-423 (1991).
14. Speakman, J. R. The evolution of flight and echolocation in bats: another leap in the dark. Mammal Rev. 31, 111-130 (2001).

15. Simmons, N. B. in Ecology, Evolution, and Behavior of Bats (eds Racey, P. A. \& Swift, S. M.) 27-43 (Oxford Univ. Press, Oxford, 1995).

16. Arita, H. T. \& Fenton, M. B. Flight and echolocation in the ecology and evolution of bats. Trends Ecol. Evol. 12, 53-58 (1997).

17. Jones, G. \& Teeling, E. C. The evolution of echolocation in bats. Trends Ecol. Evol. 21, 149-156 (2006).

18. Schutt, W. A. \& Simmons, N. B. Morphology and homology of the chiropteran calcar, with comments on the phylogenetic relationships of Archaeopteropus. J. Mamm. Evol. 5, 1-32 (1998).

19. Jepsen, G. L. Early Eocene bat from Wyoming. Science 154, 1333-1339 (1966).

20. Clyde, W. C., Sheldon, N. D., Koch, P. L., Gunnell, G. F. \& Bartels, W. S. Linking the Wasatchian/Bridgerian boundary to the Cenozoic Global Climate Optimum: new magnetostratigraphic and isotopic results from South Pass, Wyoming. Palaeogeogr. Palaeoclimatol. Palaeoecol. 167, 175-199 (2001).

21. Storch, G., Sigé, B. \& Habersetzer, J. Tachypteron franzeni, n. gen., n. sp., earliest emballonurid bat from the middle Eocene of Messel (Mammalia, Chiroptera). Paläontol. Z. 76, 189-199 (2002).

22. Novacek, M. J. Evidence for echolocation in the oldest known bats. Nature 315, 140-141 (1985).

23. Novacek, M. J. Auditory features and affinities of the Eocene bats /caronycteris and Palaeochiropteryx (Microchiroptera, incertae sedis). Am. Mus. Novitat. 2877, 1-18 (1987).

24. Habersetzer, J. \& Storch, G. Cochlea size in extant Chiroptera and Middle Eocene Microchiroptera from Messel. Naturwissenchaften 79, 462-466 (1992).

25. Gunnell, G. F. et al. Oldest placental mammal from sub-Saharan Africa: Eocene microbat from Tanzania-evidence for early evolution of sophisticated echolocation. Palaeontol. Elect. 5, 1-10 (2003).

26. Vaughan, T. A. in About Bats (eds Slaughter, B. H. \& Walton, W. D.) 127-143 (Southern Methodist Univ. Press, Dallas, TX, 1970).

27. Norberg, U. M. in Bat Flight-Fledermausflug, Bionia Report 5 (ed. Nachtigall, W.) 13-26 (Gustav Fischer, Stuttgart, 1986).

28. Rayner, J. M. V. in Bat Flight-Fledermausflug, Bionia Report 5 (ed. Nachtigall, W.) 27-74 (Gustav Fischer, Stuttgart, 1986).

29. Rayner, J. M. V. Bounding and undulating flight in birds. J. Theor. Biol. 117, 47-77 (1985).

30. Schutt, W. A. \& Simmons, N. B. in Functional and Evolutionary Ecology of Bats (eds Zubaid, A., McCracken, G. \& Kunz, T.) 15-159 (Oxford Univ. Press, Oxford, 2006).

Supplementary Information is linked to the online version of the paper at www.nature.com/nature.

Acknowledgements We thank I. Morrison for preparing the holotype specimen of Onychonycteris finneyi; A. Aase and H. Galliano for help in obtaining photographs and casts of the paratype; B. Miljour and P. Wynne for their assistance with figures; B. Boyle for photographs; and P. Myers, L. Grande, W. Simpson, M. Engstrom,

J. Eger, S. Woodward, S. Schaal, G. Storch, N. Micklich, D. Lunde, E. Westwig and C. Norris for access to specimens. Students sponsored by the Undergraduate Research Opportunities Program (UROP) at the University of Michigan were involved in data acquisition and compilation. Funding was provided by the United States National Science Foundation and Deutsche Forschungsgemeinschaft DFG.

Author Information Morphological data used in phylogenetic analyses are deposited in MorphoBank and can be obtained at http:// morphobank.geongrid.org/permalink/?P104. Reprints and permissions information is available at www.nature.com/reprints. Correspondence and requests for materials should be addressed to N.S. (simmons@amnh.org). 


\section{METHODS}

Measurements. Measurements were gathered in several ways. Standard skeletal and cranial measurements were made on specimens housed in the University of Michigan Museum of Zoology (UMMZ) and Museum of Paleontology (UM), the Royal Ontario Museum (ROM), the Field Museum of Natural History (FMNH) and the American Museum of Natural History (AMNH). All measurements were recorded to the nearest tenth (in some cases hundredth) of a millimetre. Comparative measurements of some fossils (Supplementary Table 1) and values for aspect ratio index (Supplementary Table 2) and tip length and tip area ratios (Supplementary Fig. 10) were taken primarily from the literature and supplemented with additional data as noted.

Cochlear width (oblique diameter along the first half turn of the cochlea) and basicranial width (distance between the outer margins of both horizontal semicircular canals) were measured from X-ray microradiographs of specimens housed in the Senckenberg Museum (SM). Data were collected for 549 bat species (including 89 small pteropodids). Microradiographs were made with a Faxitron 43804 X-ray cabinet (Hewlett Packard) and a microfocus X-ray tube (Feinfokus) on NDT 35 film (Dupont) or Ortho 25 film (Agfa). Each skull was placed separately into the centre beam of the X-ray apparatus to obtain a distortion-free image on the film plate. X-ray negatives were projected on an $x y$ measuring table with resolution of $0.04 \mathrm{~mm}$.

Cochlear width across the first half-turn and basicranial width of Onychonycteris finneyi were measured both from X-rays of the skull and directly from the holotype specimen with a measuring reticule. Because the bullae and the promontoria were flattened and crushed in both the left and right ear regions (Supplementary Fig. 2), our estimate of cochlear width remains somewhat tentative. However, we strove to minimize preservational effects by repeated measurement sessions and were careful not to underestimate cochlear size.

Dating. All bats known from the Green River Formation come from the Fossil Butte Member. The holotype and paratype specimens of Onychonycteris finneyi were found in the Sandwich Beds, which lie stratigraphically below the 18 Inch Layer that yielded the holotype of Icaronycteris index ${ }^{19}$. However, other specimens of Icaronycteris index have been recovered from the Sandwich Beds, so Onychonycteris finneyi and Icaronycteris index may be considered contemporaneous.

The lithostratigraphic Fossil Butte Member is contained within Wasatchian biochronological zone Wa7, which represents the late early Eocene (also known as the Lostcabinian). The Fossil Butte Member is placed within biochron Wa7 for two reasons. First, the Wa7 index taxon Lambdotherium popoagicum occurs in Fossil Butte Member sediments. Second, the Fossil Butte Member inter-fingers with uppermost beds of the Main Body of the fluvial Wasatch Formation, which contain a typical Wa7 terrestrial faunal assemblage ${ }^{31,32}$. The base of Biochron Wa7 is dated at $52.5 \mathrm{Myr}$ old $^{33}$. Accordingly, because the Sandwich Beds are near the base of the Fossil Butte Member, we believe that a 52.5-Myr date for the first occurrence of Onychonycteris is a reasonable estimate.

Phylogenetic analyses. The morphological data (including character descriptions, scorings and images) used in our phylogenetic analyses are available online on the MorphoBank website at http://morphobank.geongrid.org/permalink/ ?P104. This data set, which includes 207 characters, is a modified version of one originally published in ref. 34. Significant changes include the addition of new data for Onychonycteris, the removal of a poorly known fossil taxon (Tanzanycteris) and the treatment of Vespertilionidae and Miniopteridae as distinct families. All family-level taxa of bats are represented, as well as the best-preserved Eocene fossil genera (Icaronycteris, Archaeonycteris, Palaeochiropteryx and Hassianycteris). Five outgroup taxa were included to root the trees: a tree shrew (Tupaia glis), gliding lemur (Cynocephalus volans), hedgehog (Erinaceus europaeus), pig (Sus scrofa) and cat (Felis catus).

Phylogenetic analyses of the new data set were conducted with the parsimony algorithm implemented in PAUP* version 4.0b3a (ref. 35). A heuristic search using a random-addition sequence and 1,000 repetitions was used to find the most parsimonious trees. Near-most parsimonious trees (one to ten steps longer) were identified in subsequent heuristic searches by using the same parameters, and a decay analysis was performed by following the methods of ref. 36. A bootstrap analysis using heuristic methods (random-addition sequence, 10 repetitions for each of 1,000 bootstrap replicates) was also used to evaluate the relative support for various groupings. MacClade version 3.0 (ref. 37) was used for data entry and examination of character-state distributions.

The new data set was analysed in two ways. In one analysis (Supplementary Fig. 5) the positions of all taxa were determined solely by the morphological data, whereas in a second analysis (Fig. 4 and Supplementary Fig. 6) relationships between extant lineages were constrained by using a molecular backbone constraint tree based on ref. 38 for bat relationships and on ref. 3 for the outgroups. Fossils were not required to fall outside the extant bat crown clade or extant bat superfamilies. Topology of the constraint tree was as follows: ((Tupaia, Cynocephalus), (Felis, Sus, Erinaceus, ((Pteropodidae, ((Hipposideridae, Rhinolophidae), ((Megadermatidae, Craseonycteridae), Rhinopomatidae $))$, ((Emballonuridae, Nycteridae), (Myzopodidae, (Mystacinidae, (((Furipteridae, Noctilionidae), Thyropteridae), (Mormoopidae, Phyllostomidae)))), (((Miniopteridae, Vespertilionidae), Molossidae), Natalidae $))))$.

31. Buchheim, H. P. Paleoenvironments, lithofacies and varves of the Fossil Butte Member of the Eocene Green River Formation, southwestern Wyoming. Contrib. Geol. Univ. Wyoming 30, 3-14 (1994).

32. Grande, L. \& Buchheim, H. P. Paleontological and sedimentological variation in early Eocene Fossil Lake. Contrib. Geol. Univ. Wyoming 30, 33-56 (1994).

33. Woodburne, M. O. in Late Cretaceous and Cenozoic Mammals of North AmericaBiostratigraphy and Geochronology (ed. Woodburne, M. O.) 315-343 (Columbia Univ. Press, New York, 2004).

34. Gunnell, G. F. \& Simmons, N. B. Fossil evidence and the origin of bats. J. Mamm. Evol. 12, 209-246 (2005).

35. Swofford, D. L. PAUP*. Phylogenetic Analysis Using Parsimony (*and Other Methods) Version 4 (Sinauer Associates, Sunderland, MA, 2001).

36. Bremer, $K$. The limits of amino acid sequence data in angiosperm phylogenetic reconstructions. Evolution Int. J. Org. Evolution 42, 795-803 (1988).

37. Maddison, W. P. \& Maddison, D. R. MacClade: Analysis of Phylogeny and Character Evolution Version 3.0 (Sinauer Associates, Sunderland, MA, 1992).

38. Miller-Butterworth, C. M. et al. A family matter: conclusive resolution of the taxonomic position of the long-fingered bats, Miniopterus. Mol. Biol. Evol. 24, 1553-1561 (2007). 